\title{
Computational image analysis of Suspension Plasma Sprayed YSZ coatings
}

\author{
Monika Michalak ${ }^{*}$, Leszek Łatka ${ }^{1}$, Patrycja Szymczyk $^{1}$ and Pawet Sokołowski ${ }^{1}$ \\ ${ }^{1}$ Faculty of Mechanical Engineering, Wroclaw University of Science and Technology, Łukasiewicza 5, 50-371 Wrocław, Poland
}

\begin{abstract}
The paper presents the computational studies of microstructure- and topography- related features of suspension plasma sprayed (SPS) coatings of yttria-stabilized zirconia (YSZ). The study mainly covers the porosity assessment, provided by ImageJ software analysis. The influence of boundary conditions, defined by: (i) circularity and (ii) size limits, on the computed values of porosity is also investigated. Additionally, the digital topography evaluation is performed: confocal laser scanning microscope (CLSM) and scanning electron microscope (SEM) operating in Shape from Shading (SFS) mode measure surface roughness of deposited coatings. Computed values of porosity and roughness are referred to the variables of the spraying process, which influence the morphology of coatings and determines the possible fields of their applications.
\end{abstract}

\section{Introduction}

The paper aims at demonstrating the computational methods of image analysis, including porosity, morphology and topography assessment of plasma sprayed coatings.

Currently, one of the most extensively studied deposition methods is suspension plasma spraying (SPS). The method originates from conventional atmospheric plasma spraying (APS). SPS was developed in order to spray fine-grained powders that cannot be deposited by APS. On one hand, SPS is a very versatile technique (applied amongst others in energy, aerospace, mechanical and petrochemical industries) and provides a variety of coating microstructures [1-3]. However, on the other hand, the final coating's properties are highly dependent on the deposition parameters. APS spraying is already known to have 50 variables [4], but SPS method is even more complex (for example, the suspension properties highly influence process characteristics) [5-8]. Therefore, in this work, two types of SPS coatings with different microstructures (porous and dense) are investigated.

The evaluation of coating porosity, especially suspension plasma sprayed ones, is a challenging task. As already proven $[1,8]$, different scaled porosity can be observed. In general, many characterization techniques may be used for porosity analysis. The basic ones are [1,9-16]:

(i) water adsorption (WA): inexpensive and single method; does not measure closed porosity;

(ii) mercury intrusion porosimetry (MIP): evaluates only open porosity but provides detailed information on pore size distribution; (iii) helium pycnometry (HP): measures open porosity but does not provide the pore size distribution;

(iv) image analysis (IA): the object of interest of this paper; this method detects both open and close pores, allows to determine distribution of pore size; magnification and image contrast can influence the results;

(v) 3D reconstruction phase contrast by X-ray microscope (3D XRM): measures both open and close pores, with the size of pores up to $50 \mathrm{~nm}$; a new and expensive technique; (vi) NMR cryoporometry: measures pores down to nanometre size, approximates pore shape, a new technique.

The manner of porosity evaluation is classified differently by the literature [1,17-20]. Two main approaches can be distinguished: (i) shape-based [1,16$18]$, and (ii) size-related $[1,16,17,20]$. Notwithstanding a considered approach, the computations have to be carried out repetitively for a certain amount of images. Ganvir et al. [1] conducted such study for 20 images per sample. The ASTM Standard [12] defines the accuracy of results as dependent on the number of micrographs and 20 images is the minimum that should be taken to receive reliable results.

When investigating the porosity, pore shape should be considered. Deshpande et al. [17] distinguishes three types of pores: globular, interlamellar and cracks. The same is proposed by Ganvir et al. [1]. Authors of [18] evaluate the porosity at the following levels: (i) $0.25-1$, (ii) $0.50-1$ and (iii) $0.75-1$ (where 1 stands for perfectly round shape).

Another important parameter is pore size. As suggested in [1], the porosity of SPS YSZ coatings can be divided into nano-, submicron- and micron- scale. Moreover, pores above $10 \mu \mathrm{m}$ are considered to be

\footnotetext{
*Corresponding author: monika.michalak@pwr.edu.pl
} 
globular pores, large inter-columnar spacing and/or larger vertical and horizontal cracks [1]. This assumption is consistent with the approach of Friis [20], which diversified pores into small and large groups (large were those of at least two splat thicknesses). Deshpande [17] evaluates the porosity in the subsequent limits: 3.0-10.0 $\mu \mathrm{m}$ for coarse globular pores, $0.1-3.0 \mu \mathrm{m}$ for fine pores resulting from incomplete contact between lamellae during coating formation and $0.01-0.5 \mu \mathrm{m}$ for fine cracks, derived from the relaxation of stresses occurred during splats cooling. The limitation of pore sizes depends on many factors.

An innovative approach of this paper is to study the relationships between the mentioned parameters by computational means. In this work, ImageJ public domain free software is the computational tool used for porosity evaluation. The reliability of this method is assumed to give $95 \%$ confidence level [21]. Nevertheless, the great attention has to be paid to this technique $[1,2,5]$. The total coatings porosity (including both nano- and micropores) is of significant meaning: it affects the wide range of coating properties, such as: elastic modulus, thermal conductivity, dielectric behaviour and many others $[3,5,15,17,22]$.

The surface topography is also the important issue when characterizing coatings. The classic problem in computer imaging is the proper recovery of the shape of strongly irregular surfaces. The novel method, called shape from shading (SFS) is considered in this paper. In this technique, the 3D shape of a surface is computed from one or more 2D images $[23,24]$. The $3 \mathrm{D}$ views of the coating surfaces reconstructed by SFS are believed to give another insight on the surface profile and morphology [5].

\section{Materials and method}

\subsection{Powders and suspension characterization}

Yttria-stabilized zirconia (YSZ) powder (Tosoh TZ-8YS, Tokyo, Japan), with a chemical composition of $\mathrm{ZrO}_{2}+14$ wt. $\%$ of $\mathrm{Y}_{2} \mathrm{O}_{3}$ was used for suspension preparation. The powder particle size (Zetasizer Nano ZS, Malvern Instruments Ltd., Worcestershire, UK) was: $d v_{10}=0.36$ $\mu \mathrm{m}, d v_{50}=0.53 \mu \mathrm{m}$ and $d v_{90}=0.95 \mu \mathrm{m}$.

Each suspension was a mixture of: (i) 10 wt.\% of solid powder, (ii) solvent (ethanol and water, in ratio 1:1) and (iii) dispersant (Beycostat C213, CECA, La GarenneColobes, France). The suspension formulation process was described in details in [8].

\subsection{Substrate preparation}

The $2 \mathrm{~mm}$ thick, 304L stainless steel coupons of $25 \mathrm{~mm}$ were grit-blasted prior to the spraying. The substrate roughness was equal to $\mathrm{Ra}=7.8 \mu \mathrm{m}$ (Fig. 1.). The details of substrate preparation were presented in work [8]. a
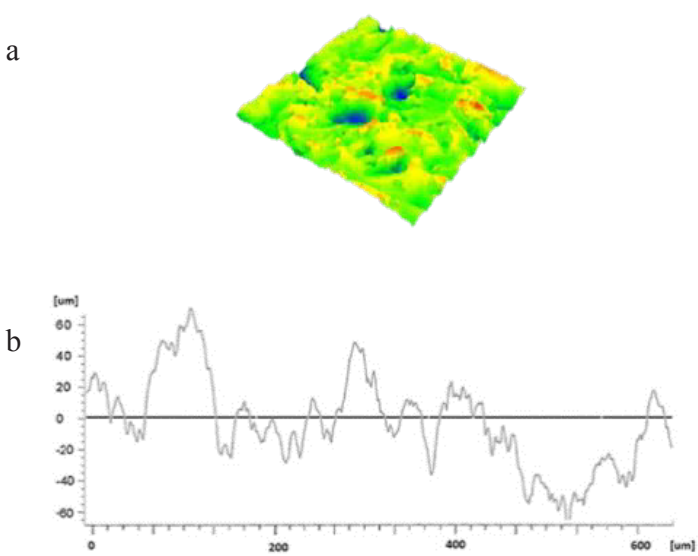

Fig. 1. The topography (a) and roughness profile (b) of substrate after grit blasting.

\subsection{Spraying description}

The coatings deposition was carried out with the use of two high-energy plasma torches: (i) Axial III (Mettech, North Vancouver, Canada) at University West (Trollhättan, Sweden) and (ii) WSP-H 500 at Institute of Plasma Physics CAS (Prague, Czech Republic). The torches were different in the terms of construction, plasma arc stabilization, feedstock injection, etc. (Table 1.). Consequently, all parameters were individually set for WSP-H 500 and Axial III. The aimed thickness of both kinds of YSZ coatings was $150 \mu \mathrm{m}$ [8].

Table 1. The spray process details [8].

\begin{tabular}{|c|c|c|}
\hline Torch & $\begin{array}{l}\text { WSP-H } 500 \\
\text { (Sample 1) }\end{array}$ & $\begin{array}{c}\text { Axial III } \\
\text { (Sample 2) }\end{array}$ \\
\hline $\begin{array}{c}\text { Electric power, } \\
\mathrm{kW}\end{array}$ & $\sim 150$ & $\sim 120$ \\
\hline $\begin{array}{l}\text { Working gases } \\
\text { composition }\end{array}$ & $\begin{array}{c}\mathrm{Ar}+\mathrm{H}_{2} \mathrm{O} \\
\text { decomposition } \\
\text { products }\end{array}$ & $\mathrm{Ar}+\mathrm{H}_{2}+\mathrm{N}_{2}$ \\
\hline $\begin{array}{c}\text { Total plasma } \\
\text { gases flow rate, } \\
\text { slpm }\end{array}$ & $\begin{array}{c}15 \mathrm{Ar}+\mathrm{H}_{2} \mathrm{O} \\
\text { decomposition } \\
\text { products }\end{array}$ & 245 \\
\hline $\begin{array}{l}\text { Stand-off } \\
\text { distance, } \\
\text { mm }\end{array}$ & 100 & 75 \\
\hline $\begin{array}{c}\text { Relative torch } \\
\text { scan speed, } \mathrm{mm} / \mathrm{s}\end{array}$ & $\sim 900$ & $\sim 1000$ \\
\hline $\begin{array}{l}\text { Offset between } \\
\text { plasma } \\
\text { torch passes, } \mathrm{mm}\end{array}$ & 30 & 5 \\
\hline $\begin{array}{c}\text { Nozzle injector } \\
\text { internal diameter, } \\
\mathrm{mm}\end{array}$ & 0.35 & 0.50 \\
\hline $\begin{array}{l}\text { Suspension } \\
\text { injection } \\
\text { system }\end{array}$ & $\begin{array}{c}\text { Pneumatic } \\
\text { system; } \\
\text { continuous } \\
\text { stream injector }\end{array}$ & $\begin{array}{c}\text { Peristaltic pomp; } \\
\text { continuous } \\
\text { stream injector }\end{array}$ \\
\hline $\begin{array}{l}\text { Suspension } \\
\text { injection } \\
\text { rate, } \mathrm{ml} / \mathrm{min}\end{array}$ & $90-100$ & 45 \\
\hline Injector type & $\begin{array}{l}\text { Nozzle outside } \\
\text { the torch, } \\
\text { injection realized } \\
\text { radially }\end{array}$ & $\begin{array}{l}\text { Nozzle inside the } \\
\text { torch, } \\
\text { injection realized } \\
\text { axially }\end{array}$ \\
\hline
\end{tabular}




\subsection{Porosity analysis}

In order to study the coatings microstructures, the specimens were firstly sectioned and embedded in a low viscosity epoxy resin. A standard procedure was applied to polish the samples manually. Gold sputtering was used prior to SEM investigations (Phenom G2 pro, PhenomWorld B.V., Eindhoven, the Netherlands) to reduce the charging effect on ceramics.

Porosity analysis was carried out by the use of ImageJ software (ImageJ is free, open source software for images processing. It enables to calculate the area- or pixel- based statistics of user-defined settings [18]). The preceding stage before computational evaluation was the acquisition of SEM images in order to verify the scale of pores. Nanometre- (below 0.1 $\mu \mathrm{m}$ ), submicrometre- (0.1-1.0 $\mu \mathrm{m})$ and micrometre- sized (above $1.0 \mu \mathrm{m}$ ) pores are all observed in SPS coatings (Fig. 2.). The pores can be either round or irregular.

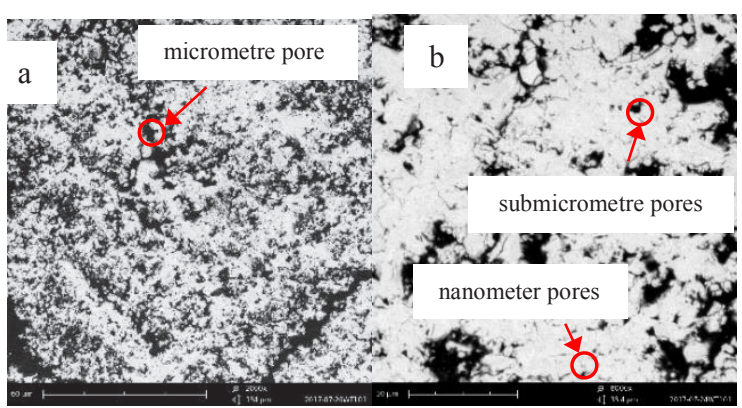

Fig. 2. SEM images of coating of sample 1 at various magnifications: $\times 2000$ (a) and $\times 8000$ (b), showing two different scales of porosity.

In this work the porosity was investigated with the use of micrographs taken at two magnifications (similarly as in [1]): (i) lower magnification for micrometre-sized pores, big cracks and column gaps, (ii) the higher magnification for submicrometre- and nanometre-sized pores. The images were taken at magnifications of $\times 2000$ and $\times 8000$. A total of 30 SEM micrographs were recorded across the $25 \mathrm{~mm}$ cross-section of coating in each case. All images were converted into binary files prior to the porosity calculations.

To sum up, the investigations cover the study of the following variables (Fig. 3. and Fig. 4.):

(i) Magnification: $\times 2000$ and $\times 8000$,

(ii) Circularity (which stands for the factor assessing the globularity of pores; its value is between 0 and $1 ; 1$ stands for perfectly rounded pores): five circularity ranges were applied: $0.00-0.25 ; 0.26-0,50 ; 0.51-0.75 ; 0.76-1.00 ; 0.00$ 1.00,

(iii) Pore size: nanometre-sized $\quad(0.01-0.1 \mu \mathrm{m})$, submicrometre-sized $(0.1-1.0 \mu \mathrm{m})$, micrometre-sized $(1.0-10.0 \mu \mathrm{m})$, coarse $(>10.0 \mu \mathrm{m})$ and pores with no size limits,

(iv) Structure type: porous (sample 1) and dense (sample 2) coatings.

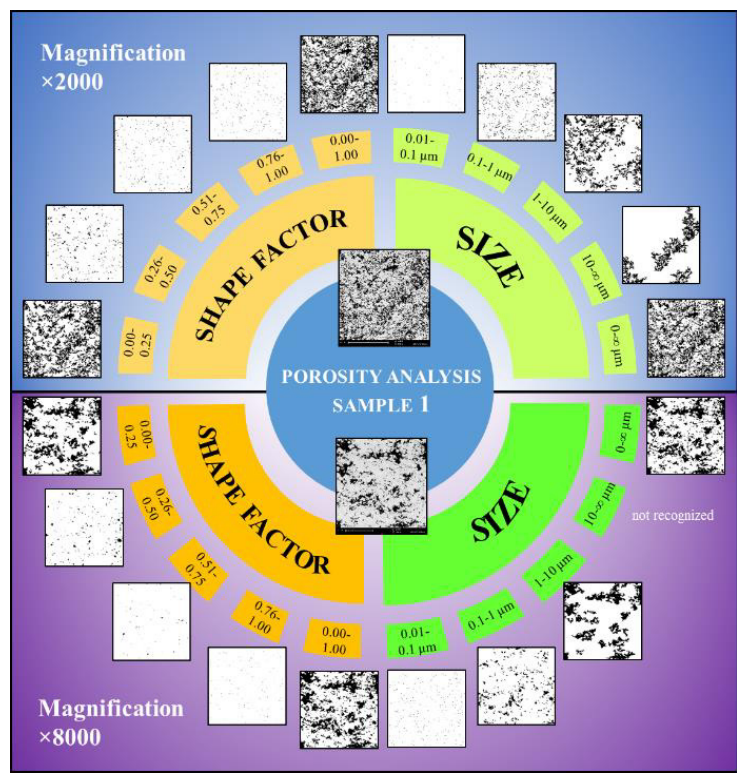

Fig. 3. The scope of investigations for the sample 1 (sprayed by WSP-H 500).

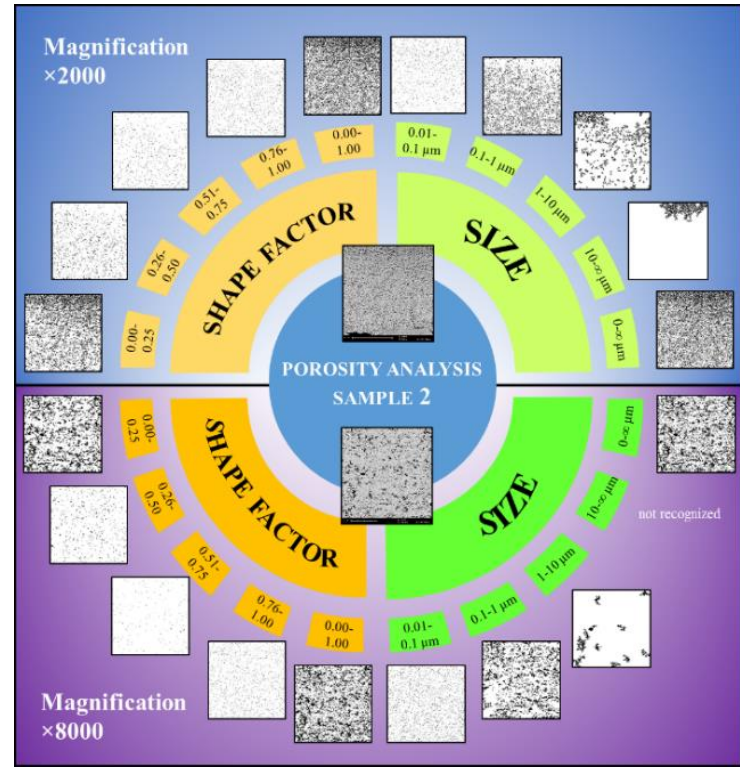

Fig. 4. The scope of investigations for the sample 2 (sprayed by Axial III).

For both shape- and size- related analyses, the porosity analysis covered the following steps. (Fig. 5.): (i) firstly, the image was opened (if bimodal grey value 8-bit was not set yet, it should be done here). (ii) Next, the image was calibrated by adjust to the scale bar. (iii) Subsequently, the image was cropped to the rectangle which comprises only the coating (e.g.: the substrate was not included; the intercolumnar areas between columns, visible at low magnification, were not excluded from the analysis). (iv) The threshold for the image processing was applied and (v) finally the porosity value was calculated. 


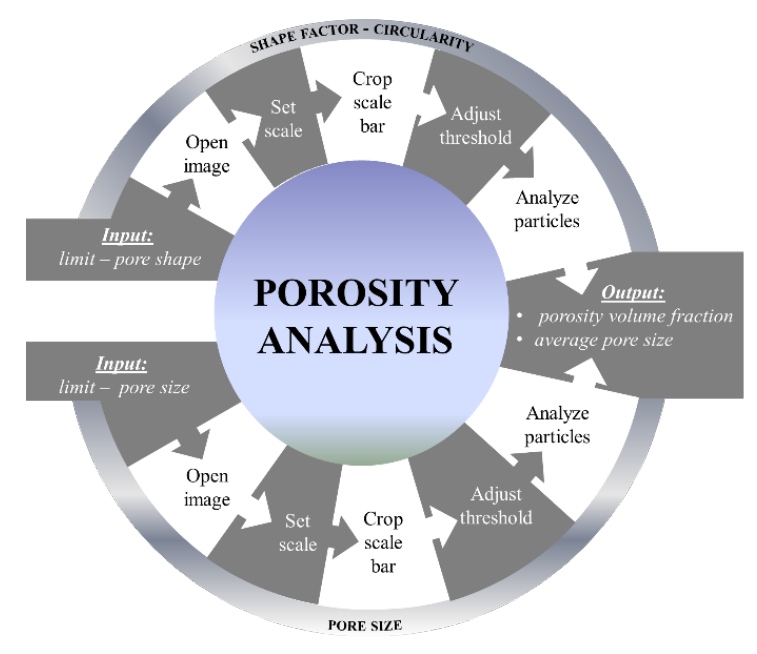

Fig. 5. The steps of image analyses.

The threshold is particularly important to correctly distinguishing the pores (Fig. 6.). There are many threshold methods (e.g.: Intermodes, IsoData, MaxEntropy, Minimum, Percentile, etc.). In order to set the suitable one, each method was tested in this study. The most appropriate threshold was assumed to be Mean.
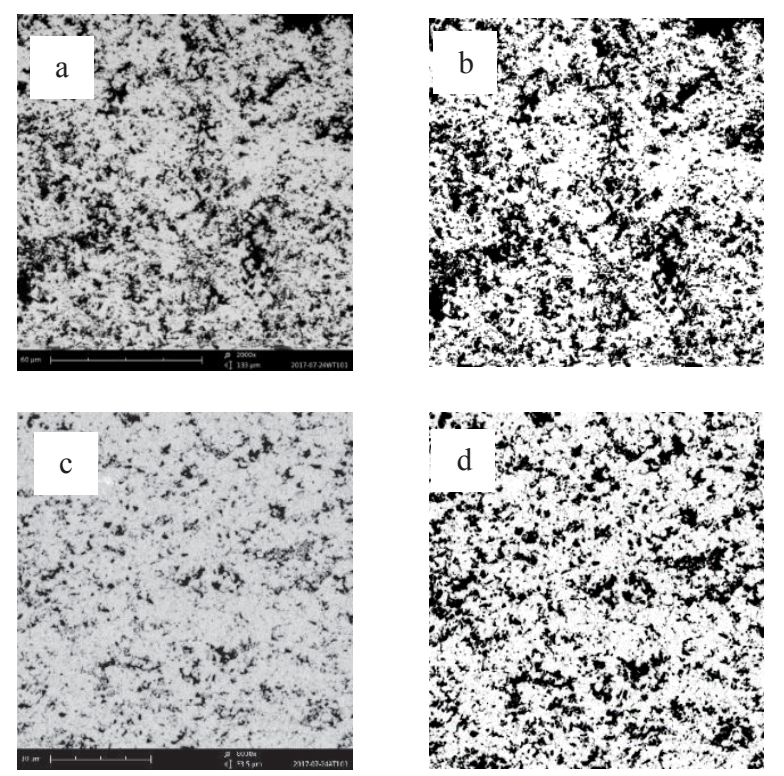

Fig. 6. SEM images before (a - sample 1, x 2000; c-sample 2, x 8000) and after threshold (b-sample 1, x 2000; d - sample $2, \mathrm{x} 8000)$.

\subsection{Characterization of coatings topography}

In order to study the coatings topography, the roughness was measured with the use of: (i) non-contact confocal laser scanning microscopy (CLSM, Olympus LEXT OLS4000, Tokyo, Japan) and (ii) 3D Roughness Reconstruction application, dedicated for Phenom G2 pro (Phenom-World B.V., Eindhoven, The Netherlands) scanning electron microscope (SEM). SFS technique was applied to visualize coating free-surface in 3D mode. The views were created automatically by assembling four SEM micrographs, taken by symmetrically located BSD detectors (Phenom G2 pro, Phenom-World B.V., Eindhoven, the Netherlands). More details on SFS are provided in work [25].

\section{Results}

\subsection{Morphology of coatings}

The microstructure analysis of sample 1 reveals porous and columnar-like microstructure (Fig. 7a.). The coating thickness is in the range of 170 to $180 \mu \mathrm{m}$. The structure contains vertical voids but also a great number of closed pores. The pores aggregate reaches the total size of even a few micrometres. This coating has a typical cauliflowerlike surface (Fig. 7b.).

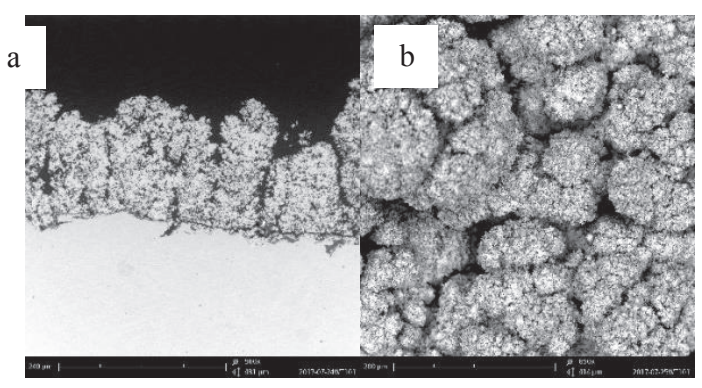

Fig. 7. The morphology of columnar-like coating of sample 1: $\mathrm{a}$ - columnar like structure of cross-section, $\mathrm{b}$ - cauliflower morphology of coating surface.

The coating labelled as sample 2 is $120-130 \mu \mathrm{m}$ thick. The use of an Axial III plasma torch caused the formation of a very dense-looking coating and the columnar-like microstructure is not observed (Fig. 8a.). Nevertheless, although the coating seems to be dense, the pores are still present in the structure. Those pores are expected to be of a very small size (in the range of hundreds of nanometres) and uniformly distributed in the coating. They do not form bigger clusters as it was observed in the coating of sample 1. The top view of coating indicates the fine-grained nature of deposits (Fig. 8b.).

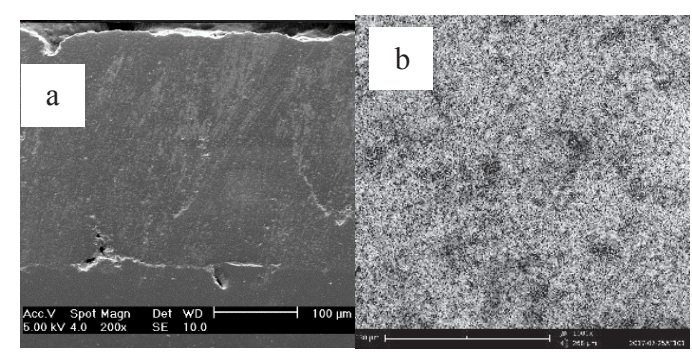

Fig. 8. The morphology of dense coating of sample 2: $\mathrm{a}-$ cross-section view, $\mathrm{b}$ - top view morphology.

More advanced topography features were provided by SFS technique (Fig. 9. and Fig. 10). The coating of sample 1 reveals columnar microstructure. The $R a$ roughness of this coating is two times higher in comparison with the dense and relatively smooth coating of sample 2 (Table 2.). The results were confirmed both by SEM (in SFS 
mode) and non-contact confocal laser scanning microscope (CLSM).

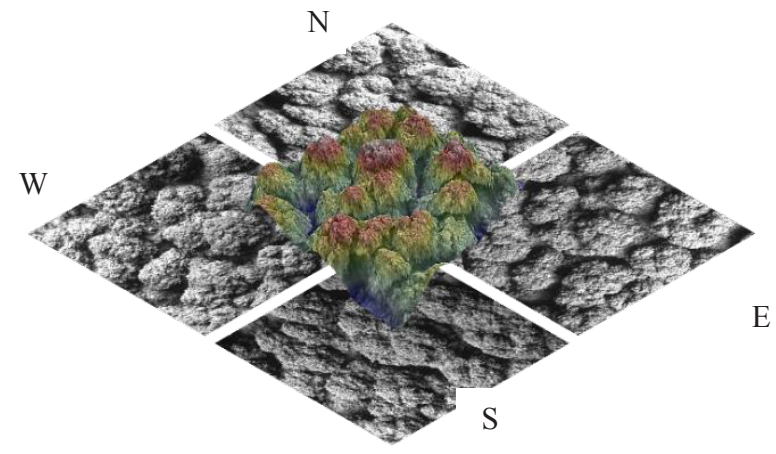

Fig. 9.Shape from shading: the partial 2D images and computed 3D shape of sample 1 (shown in Fig. 2); 650x.

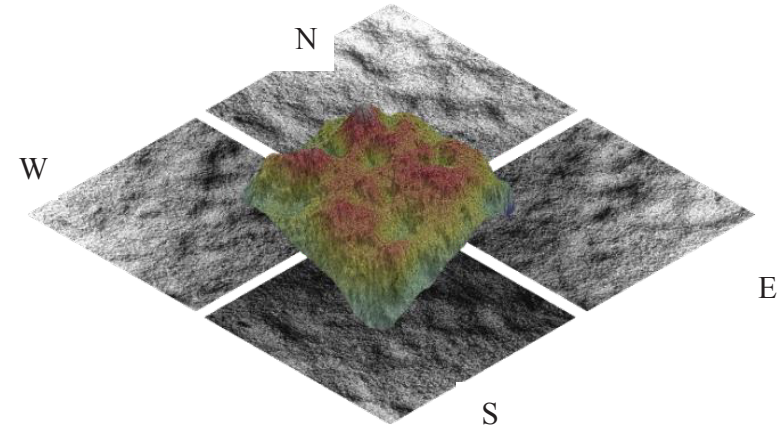

Fig. 10. Shape from shading: the partial 2D images and computed 3D shape of sample 2 (shown in Fig. 3); 650x.

Table 2. Roughness $R a$ of coatings measured by SEM (SFS) and CLSM

\begin{tabular}{|l|c|c|}
\hline & Sample 1 & Sample 2 \\
\hline $\begin{array}{l}\text { SEM } \\
\text { Phenom G2 pro }\end{array}$ & $15.9 \pm 1.5 \mu \mathrm{m}$ & $7.7 \pm 0.7 \mu \mathrm{m}$ \\
\hline $\begin{array}{l}\text { CLSM } \\
\begin{array}{l}\text { Olympus LEXT } \\
\text { OLS4000 }\end{array}\end{array}$ & $14.1 \pm 1.6 \mu \mathrm{m}$ & $4.5 \pm 0.5 \mu \mathrm{m}$ \\
\hline
\end{tabular}

\subsection{Porosity evaluation}

\subsubsection{Size influence}

In the pore size-based studies, images were analysed for different size ranges, specified already in chapter 2.4. The results were obtained for: (i) total volume fractions of pores, (ii) percent relative accuracy, described in ASTM Standards [12] and (iii) the average size of pore.

\subsection{Volume fraction}

The computed pore volume fractions show different behaviour for coatings that were sprayed by Axial III and H-WSP 500 plasma torch (Fig. 11.). Pores in sample 1 are mainly micrometre in size. Coating of sample 2 contains both submicrometre - and micrometre-sized pores. The results confirm that the coating of sample 1 is porous, whilst the coating of sample 2 - more dense. It is recommended to distinguish the range of analysed pores. The results without the diversified size, although still valid (see next chapter), provides less detailed data.

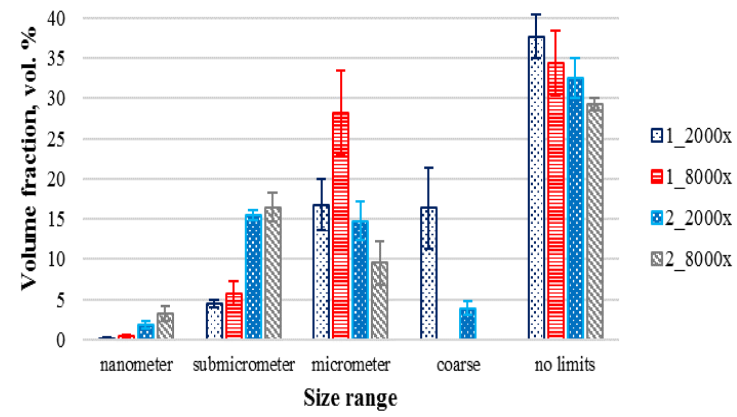

Fig. 11.The total volume fractions of pores, computed for different pore sizes.

\subsection{Relative accuracy}

The porosity determination is not complete without the calculation of its precision within normal confidence. According to ASTM E2109-01 (2014) [12], the common engineering practice assumes normal confidence as the expectation that the actual is within the stated uncertainty $95 \%$ of the time. One of the factors which assesses the reliability of the results, is the percent relative accuracy, $\% R A$ (equation 1), calculated for the $95 \%$ confidence interval (equation 2).

$$
\begin{gathered}
\% R A=\frac{95 \% C I}{\bar{X}} \cdot 100 \\
95 \% C I=\frac{t \cdot s}{\sqrt{n}}
\end{gathered}
$$

$\% R A$ - the percent relative accuracy,

95\% CI $-95 \%$ confidence interval,

$\bar{x}$ - the mean volume fraction of porosity,

$t$ - constant, confidence interval multipliers,

$s$ - standard deviation of total porosity volume fraction,

$n$ - number of measurements.

ASTM E2109-01 (2014)[12] considers $R A$ equal to $10 \%$ (or lower) as acceptable precision. The percent relative accuracy values, calculated for different ranges of pore sizes, magnifications and coating's types are summarized in Fig. 12. All results are below 10\% RA value. The only inacceptable outcome is 1_2000x (sample 1 , magnification $\times 2000$ ) with the pore sizes above $10 \mu \mathrm{m}$. This suggests that the upper boundary pore size should be set as well.

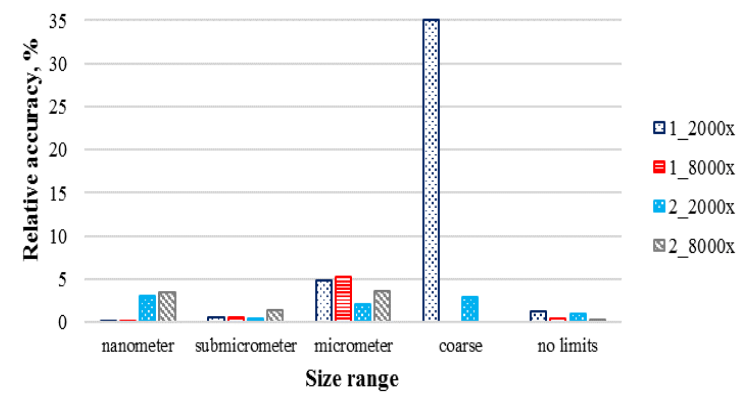

Fig. 12. The percent relative accuracy, depending on the pore size. 


\subsection{Average pore size}

When comparing the average pore size, depending on the limited size and applied magnification (Table 3.), it is observed that: (i) in each case, the computed results agree with restricted sizes. (ii) It is not possible to detect and measure the coarse pores $(>10 \mu \mathrm{m})$ when using higher magnification $(\times 8000)$, so for the assessment of coarse pores, the lower magnification is recommended. (iii) It is recommended to distinguish the range of analysed pores, otherwise the analysis provides more inaccurate results.

Table 3. The influence of assumed range of pore size on the computed average size of pore.

\begin{tabular}{|c|c|c|c|c|c|}
\hline \multicolumn{2}{|c|}{ Image } & $\begin{array}{c}\text { Sample } \\
1 \times \\
2000\end{array}$ & $\begin{array}{c}\text { Sampl } \\
\text { e 1 } \times \\
8000\end{array}$ & $\begin{array}{c}\text { Sample } \\
\mathbf{2} \times \\
\mathbf{2 0 0 0}\end{array}$ & $\begin{array}{c}\text { Sampl } \\
\mathbf{2} \times \\
\mathbf{8 0 0 0}\end{array}$ \\
\hline \multirow{4}{*}{ Fine } & nano, & 94.0 & 45.0 & 97.0 & 29.0 \\
& nm & \pm 5.0 & \pm 8.0 & \pm 4.0 & \pm 2.0 \\
\cline { 2 - 6 } & submicr & 639.0 & 599.0 & 578.0 & 552.0 \\
& on, nm & \pm 51.0 & \pm 45.0 & \pm 18.0 & \pm 18.0 \\
\cline { 2 - 6 } & microm & 4.9 & 5.2 & 3.3 & 2.9 \\
& etre, $\mu \mathrm{m}$ & \pm 0.2 & \pm 1.1 & \pm 0.2 & \pm 0.2 \\
\hline \multirow{2}{*}{$\begin{array}{c}\text { Coarse } \\
\text { Fine } \\
\text { and } \\
\text { coarse }\end{array}$} & $\mu \mathrm{m}$ & 35.1 & - & 27.7 & - \\
\pm 9.2 & - & \pm 3.1 & \\
\hline
\end{tabular}

\subsubsection{Shape (circularity) influence}

The influence of the pore shape (circularity) on the volume of pores was also investigated (see chapter 2.4). The circularity command calculates the globularity of object(s), by the use of area and perimeter variables (see equation 3 and Fig. 13.) [26, 27]. The circularity value of 1.00 indicates a perfect circle. As the value approaches 0.00 , it indicates an increasingly elongated polygon [26].

$$
\text { circularity }=4 \cdot \pi \cdot \frac{\text { area }}{\text { perimeter }^{2}}
$$

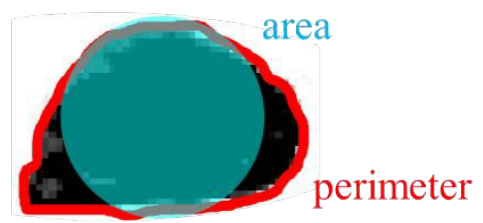

Fig. 13. Illustration of area and perimeter variables [27].

The results are calculated (for $\times 2000$ and $\times 8000$ magnifications) for: (i) total volume fractions of pores and (ii) percent relative accuracy, as specified in ASTM Standards [12].

\subsection{Volume fraction}

The dominating type of pores in both investigated samples are the ones of longitudinal shape (Fig. 14.), with the range of circularity between $0.00-0.25$. However, the dense coating of sample 2 contains a slightly lower volume of non-circular pores. The other shape ranges do not differ significantly. The sum of calculated fractions with circularities: $0.00-0.25,0.26-0.50,0.51-0.75,0.76$ 1.00 is equal to the amount of porosity identified for 0.00 1.00 range.

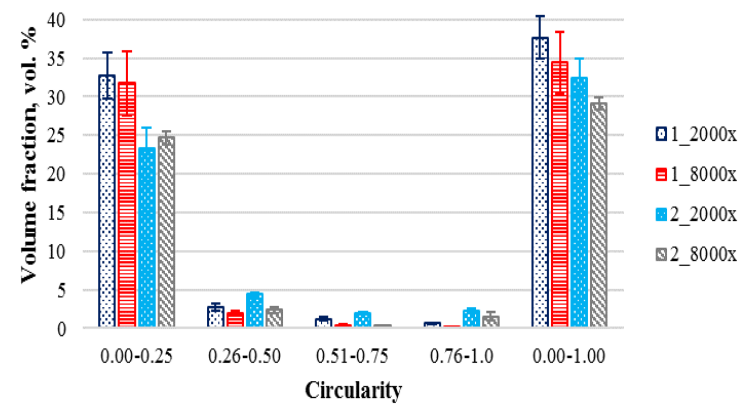

Fig. 14. The total volume fractions of pores, computed for different pore shapes.

\subsection{Relative accuracy}

Finally, the $\% R A$ was determined for shape-diversified volume fractions of pores. All calculated $95 \% R A$ values are below 10 (Fig. 15.), so the precision of porosity evaluation is satisfactory.

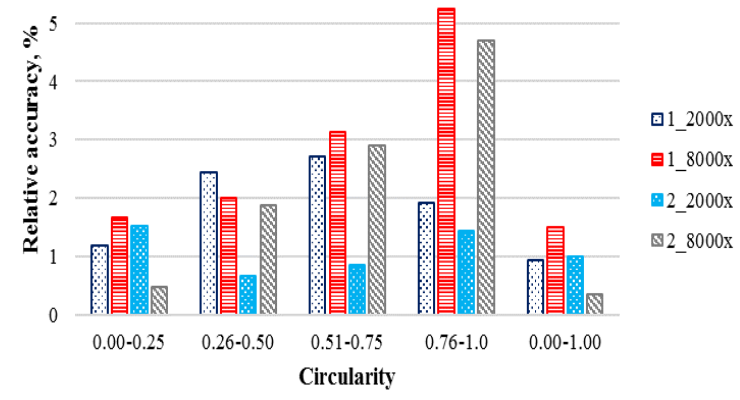

Fig. 15. The percent relative accuracy, depending on the pore shape

\section{Discussion}

The spraying of fine powder particles, like in SPS, results in coatings with a wide range of porosity. The distribution of pore size and the total number of pores depends also on the condition of spraying. For the investigated coatings, the total closed porosity (without visible inter-columnar gaps) is found to be in the range of 37 vol.\% (without discontinuities) and 29 vol.\%, for coatings of sample 1 and sample 2, respectively. Those results are consistent with the porosity investigated by Ganvir et al. [1], who compared axial suspension plasma sprayed YSZ coatings, having quite similar microstructures - the author observed both small-scaled porosity (at $\times 1000)$ and large-scaled porosity (at $\times 10000$ ), respectively in amounts of 24 and $42 \mathrm{vol} . \%$. The investigations of pore size distribution show that the dominated pores in the coating of sample 1 are those of micrometre size ( 28 vol. $\%$ with $\times 8000$ magnification). In the coating of sample 2, smaller (submicron) pores are dominating (16 vol. $\%$ with $\times 8000$ magnification). The spraying parameters result in 
formulation of porous (sample 1) or dense (sample 2) types of coatings.

As introduced above, the presented study is focused on the coatings with different types of microstructure dense and porous. The visual assessment, carried out by SEM, is consistent with the results of image analysis: the coating of sample 1 is much more porous than dense coating of sample 2 .

The roughness of the coating originates from the method of spraying, spray process parameters and substrate topography. The strong correlation between coating roughness and morphology of coatings can be also observed (compare Fig. 9. and Fig. 10. and Tab.2.). The coating of sample 1 reveals higher roughness values which is caused by the columnar type of coating. On the contrary, the coating of sample 2 is much more homogeneous and therefore has lower roughness values. The visualisation of the surface topography may be regarded as a useful tool for the evaluation of coatings.

Finally, the image analysis of the porosity in the plasma sprayed coatings has to be carried out with attention to the specified problem. The brightness and contrast (necessarily at the same level for each image), magnification (lower - better for coarse pores, higher for fine pores) and threshold (Mean mode) decided about the reliable results. In addition, the repetitive manner of image analysis is required for proper porosity computations. Properly conducted image analysis enables to characterize shape and size distribution of pores in user-friendly way, without expensive and advanced equipment (Fig. 16.).

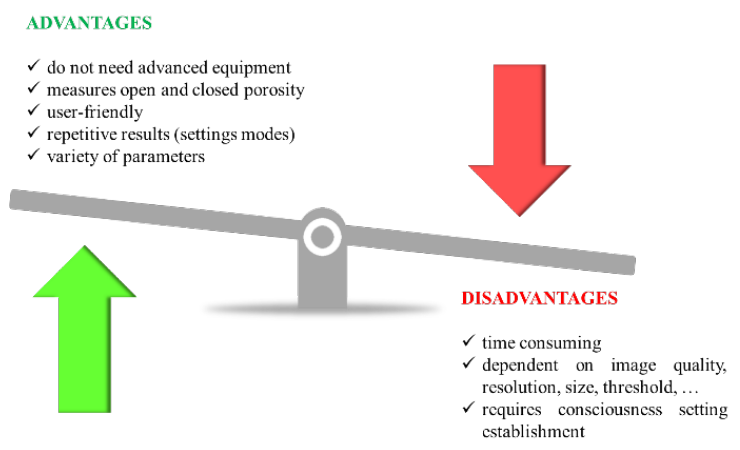

Fig. 16. The use of image processing for porosity measurements - advantages and disadvantages

\section{Summary}

As was presented in this work, the quantitative computational image analysis is an integral part of the microstructural characterization of thermally sprayed coatings. Both the literature and the article show that this tool may provide a reliable outcome - the obtained results are acceptable, especially in the terms of columnar coatings, which were tailored for thermal barrier coatings. Nevertheless, the capturing of images and their postprocessing has to be carried out with the attention to detail, as many variables (among others: magnification, limits of pore shape and size, quality of the image and others) influences the final results.
The work was financed by the research project Sonata, UMO-2013/11/D/ST8/03400, awarded to the Faculty of Mechanical Engineering at the Wroclaw University of Science and Technology by the National Science Centre (Poland). The authors would like to acknowledge the help of research group of prof. Per Nylén from University West and research group of PhD Tomáš Chráska from Institute of Plasma Physics from Prague with the coating deposition process.

\section{References}

1. A. Ganvir, N. Curry, S. Björklund, N. Markocsan, P. Nylén, J. Therm. Spray Technol. 24 (2015)

2. A. Bacciochini, G. Montavon, J. Ilavsky, A. Denoirjean, P. Fauchais, J. Therm. Spray Technol. 19 (2010)

3. A. Ganvir, N. Curry, N. Markocsan, P. Nylén, S. Joshi, M. Vilemova, Z. Pala, J. Therm. Spray Technol. 25 (2016)

4. P. Fauchais, J.L. Coudert, B. Pateyron, La production des plasmas thermiques, Rev. Générale Therm. 35 (1996)

5. P. Sokołowski, P. Nylen, R. Musalek, L. Łatka, S. Kozerski, D. Dietrich, T. Lampke, L. Pawłowski, Surf. Coat. Technol. 318 (2017)

6. F. Gitzhofer, E. Bouyer, M.I. Boulos, Suspension plasma spray, US5609921 A, 1997. http://www.google.ch/patents/US5609921 (accessed December 20, 2016).

7. R. Rampon, O. Marchand, C. Filiatre, G. Bertrand, Surf. Coat. Technol. 202 (2008)

8. P. Sokołowski, S. Kozerski, L. Pawłowski, A. Ambroziak, Surf. Coat. Technol. 260 (2014)

9. ISO/TR 26946:2011 - Standard method for porosity measurement of thermally sprayed coatings. https://www.iso.org/standard/43929.html (accessed July 17, 2017).

10. B.D. Craig, L.F. Francis, L. Abrams, J. Am. Ceram. Soc. 79 (1996)

11. M. Lawrence, Y. Jiang, Porosity, Pore Size Distribution, Micro-structure, (Bio-Aggreg. Based Build. Mater., Springer, Dordrecht, 2017)

12. ASTM E2109-01(2014) Standard Test Methods for Determining Area Percentage Porosity in Thermal Sprayed Coatings, ASTM International, West Conshohocken, PA, 2014.

13. U. Klement, J. Ekberg, S.T. Kelly, 3D Analysis of Porosity in a Ceramic Coating Using X-ray Microscopy, J. Therm. Spray Technol. 26 (2017)

14. J. Ekberg, L. Nordstierna, U. Klement, Surf. Coat. Technol. 315 (2017)

15. U. Klement, J. Ekberg, A. Ganvir, Mater. Sci. Forum. 879 (2017)

16. A. Ganvir, N. Curry, S. Govindarajan, N. Markocsan, Int. J. Appl. Ceram. Technol. 13, (2016)

17. S. Deshpande, A. Kulkarni, S. Sampath, H. Herman, Surf. Coat. Technol. 187 (2004) 
18. W. Shen, J. Wan, T. K. Tokunaga, K. Yongman, i L. Xizhe, EJGE 20 (2015)

19. F. Andreola, C. Leonelli, M. Romagnoli, P. Miselli, Am. Ceram. Soc. Bull. 79 (2000)

20. M. Friis, C. Persson, J. Wigren, Surf. Coat. Technol. 141, 115-127 (2001)

21. D.B. Fowler, W. Riggs, J.C. Russ, Adv Mater Proc., 11, 41-52 (1990)

22. A. Ganvir, N. Curry, N. Markocsan, P. Nylén, F.-L. Toma, Surf. Coat. Technol. 268, 70-76 (2015)

23. E. Prados, O. Faugeras, Shape From Shading (Handb. Math. Models Comput. Vis., Springer, Boston, 2006)
24. R. Zhang, P.-S. Tsai, J.E. Cryer, M. Shah, IEEE Trans. Pattern Anal. Mach. Intell. 21, 690-706 (1999)

25. P. Sokołowski, L. Pawłowski, D. Dietrich, T. Lampke, D. Jech, J. Therm. Spray Technol. 25, 94104 (2016)

26. W. Rasband, Circularity, (2000). https://imagej.nih.gov/ij/plugins/circularity.html (accessed July 30, 2017)

27. Public Lab: Passive Particle Monitoring Analysis, https://publiclab.org/wiki/passive-pm-analysis (accessed July 30, 2017) 